\title{
LITERATURA INFANTIL E FORMAÇÃO DE PROFESSORES DA INFÂNCIA
}

\author{
Yngrid Karolline Mendonça Costa ${ }^{1}$ \\ Cyntia Graziella Guizelim Simões Girotto ${ }^{2}$
}

Resumo: Este texto tem por objetivo trazer à reflexão elementos teórico-metodológicos direcionados para pensar a necessária tomada de consciência do profissional atuante em turmas da Educação Infantil, especialmente no que se refere às escolhas de livros literários e às atitudes leitoras. Esse processo intencionalmente organizado envolve ações anteriores à leitura para as crianças e tem valor precípuo no êxito do trabalho pedagógico potencialmente humanizador, que pode forjar o nascimento de aspectos efetivos de modos de ser leitor desde a mais tenra infância, sem se dirigir à alfabetização precoce, mas com foco no acesso a bens materiais da cultura humana historicamente acumulada e na relação ativa da criança com o livro de literatura infantil. Nossas reflexões teórico-metodológicas estão baseadas nos princípios da Teoria Histórico-Cultural, para fundamentar sobre o desenvolvimento das funções psíquicas superiores e das qualidades especificamente humanas nas crianças, e também utilizamos as ideias de Bakhtin, em relação à apropriação da língua e da linguagem. Esperamos que esse texto colabore para a prática de professores em relação à leitura, pois, por mais que hajam muitas pesquisas nessa área, quando vemos os índices nacionais sobre a formação de leitores e escritores, temos resultados avassaladores, porque as crianças estão na escola, mas a escola ainda não tem dado conta de formar subsídios para a criação de pessoas envolvidas com a leitura e escrita fora dos muros que a circundam.

Palavras-chave: Educação. Literatura Infantojuvenil. Formação de professores. Competência didática.

${ }^{1}$ Mestranda em Educação pelo Pós Graduação em Educação na Universidade Estadual Paulista "Julio de Mesquita Filho" - Faculdade de Filosofia e Ciências- campus de Marília.

2 Pós-doutorado em Leitura e Literatura Infantil pela Universidade de Passo Fundo. Doutora em Educação pela Unesp. Professora Livre-Docente adjunta na Universidade Estadual Paulista "Julio de Mesquita Filho" - Faculdade de Filosofia e Ciências- campus de Marília 


\section{WORKING MATHEMATICAL CONCEPTS BY BOWLING GAME}

Abstract: This paper presents the results of a Scientific Initiation research carried out at the State University of Maringá (UEM), in 2016, which investigated the Bowling game in mathematics teaching in the initial years of Elementary School. The purpose of the text is to present how the game, while a social product determined by human history, can be applied in the learning process of mathematical concepts. The theoretical-methodological basis of the research in Teaching-Oriented Activity (TOA), which anchors its structure in the premises of historical-cultural theory and the theory of activity as a form of organization of the teaching of mathematics, being an instrument of both teacher and student and ensuring the appropriation of theoretical knowledge (MOURA, 2010). We will discuss initially on the work with the games of rules and necessity of pedagogical intentionality for the organization of the teaching of mathematics with this resource. Then reports on the game of Bowling highlighting how the modifications have been made since its inception so much that there is no reference to materials used as the rules. Finally, we discuss from the assumptions of the TOA, how to explore this game in addition to the form traditionally present in the school context, which limits the possibilities of working with mathematical concepts. We hope that our work will be shaped as a way of assisting in the organization of mathematics teaching, since reinforcing and assuming the commitment of providing children with the conditions to be developed intellectually in the school is the role of all educators.

Keywords: Bowling Game. Mathematics Teaching. Control of quantities. Organization of education. Elementary school.

\section{TRABAJANDO CONCEPTOS MATEMÁTICOS POR EL “JUEGO DE BOLOS”}

Resumen: Este trabajo presenta los resultados de una investigación de Iniciación Científica realizada en la Universidad Estadual de Maringá - UEM en el año 2016 sobre el juego de "Bolos" utilizado como recurso para la enseñanza de matemáticas en los años iniciales de Enseñanza Primaria Fundamental. El objetivo es mostrar cómo ese juego, como producto social determinado por la historia humana, puede ser aplicado no proceso de aprendizaje de los conceptos matemáticos. La base teórico-metodológica de la investigación es una "Actividad Orientadora de Enseñanza-AOE" que se estructura a partir de los presupuestos de la teoría histórico-cultural, y de la teoría que considera la actividad como una forma de organizar la enseñanza de la matemáticas, que asegura la apropiación de los conocimientos teóricos (MOURA, 2010). Discutiremos inicialmente sobre el trabajo con juegos de reglas y la necesidad de la intencionalidad pedagógica para una organización de la enseñanza de la matemáticas con este recurso. En este artículo se muestran los cambios que se han producido en el momento de la modificación. Por fin, discutimos a partir de los presupuestos de la AOE, como explorar este juego más allá de la forma tradicionalmente presente en el contexto escolar, la cual limita las posibilidades de trabajo con conceptos matemáticos. Esperamos que nuestro estudio, sea una contribución para la organización de la enseñanza de la matemáticas, dado que reforzar y asumir el compromiso de proporcionar a los niños las condiciones para que se desarrollen intelectualmente en la escuela es función de todos los educadores.

Palabras clave: Juego de Bolos. Enseñanza de Matemáticas. Control de cantidades. Organización de la enseñanza. Enseñanza primaria 


\section{Introdução}

Nos limites deste texto, nosso objetivo central é trazer à discussão aspectos de estudos teóricos e práticos, empreendidos em nossas ações como docentes e pesquisadoras. Especialmente, focamo-nos em reflexões elaboradas em torno de questões sobre especificidades da docência na Educação Infantil e a articulação dessas questões com aquelas afetas à leitura e à literatura infantil, o que exige pensarmos com atenção a oferta e o acesso a livros de literatura infantil para crianças pequenas, considerando que uma das intervenções pedagógicas reveladoras do trabalho mediador intencional do professor da Educação Infantil é justamente a possibilidade e o oferecimento às crianças de situações educativas que possibilitem a relação ativa delas com a cultura, e, portanto, com a arte literária.

As Diretrizes Curriculares Nacionais para a Educação Infantil (BRASIL, 2009), fixadas por meio da Resolução no 5, inciso II, de dezembro de 2009, afirmam que as práticas pedagógicas devem garantir à criança experiências que "favoreçam a imersão das crianças nas diferentes linguagens e o progressivo domínio por elas de vários gêneros e formas de expressão: gestual, verbal, plástica, dramática e musical." (BRASIL, 2009, p. 4). Mas o que seriam essas diferentes linguagens, se não também aquelas relativas às artes expressadas em suas diversas manifestações, tais como a música, a literatura, o teatro? Compreendemos que a partir dessas proposições legais, fixa-se o direito fundamental das crianças de acesso à cultura, especialmente em relação aos bens culturais artísticos, além de outras defesas essenciais como o oferecimento, na Educação Infantil, de ações e atitudes ativas, o respeito à diversidade cultural, étnica e religiosa, o respeito à comunidade, ao outro, o estímulo à curiosidade infantil e à exploração, assim como outros direitos necessários para o seu pleno desenvolvimento da inteligência e da personalidade da criança pequena (BRASIL, 2009).

Para a garantia de direitos fundamentais das crianças, de acordo com as DCNEls, como documento mandatório para a organização de propostas pedagógicas na Educação Infantil, são emergentes processos de formação inicial e continuada de professores capazes de instrumentalizar teórica, didática e metodologicamente esses profissionais, de modo que possam ativar e cultivar, no exercício docente, práticas de planejamento, observação, registro, documentação e avaliação de propostas realizadas com as crianças, 
documentando o processo educativo com o uso de “[...] gravadores, projetores, computadores, máquinas fotográficas, e outros recursos tecnológicos e midiáticos." (BRASIL, 2009, p. 4), porque o registro é instrumento didático articulado à avaliação pedagógica, com vistas à constituição da práxis educativa.

Apesar do anúncio e da prerrogativa legal previstos por meio das DCNEls (BRASIL, 2009), a garantia dos direitos fundamentais das crianças ainda está longe de ser efetivada, conforme dados de pesquisa recente realizada entre as unidades da Unesp situadas em dois municípios do interior paulista, com financiamento da Fapesp e da FMCSV ${ }^{3}$ (2011-2014), intitulada "Literatura e Primeira Infância: dois municípios em cena e o PNBE (Programa Nacional Biblioteca da Escola) na formação de crianças leitoras". ${ }^{4}$ Nessa investigação, o objetivo era verificar se os livros de literatura infantil disponibilizados pelo PNBE, presentes em todas as escolas da rede pública do Brasil, circulavam nas mãos de crianças de até três anos, além de verificar a concepção dos professores acerca da importância de ofertar a leitura desde a mais tenra idade. Nesse estudo, confrontamos o questionário aplicado às profissionais participantes da pesquisa - professoras e coordenadoras que trabalhavam com crianças de até três anos nos dois municípios - com elementos da observação realizada nos espaços das escolas destinados à leitura, triangulando esses dados com a conferência dos livros disponibilizados pelo PNBE e presentes nesses espaços escolares.

Nessa investigação, o discurso da maioria das professoras assegurava a importância de ler, indicava a realização de rodas de leitura com as crianças e a contação de histórias, porém, na prática, aparentemente, essas profissionais desconheciam essa política pública de oferta de livros e estes não circulavam entre as crianças. Por vezes, os encontramos encaixotados na sala da coordenadora ou em uma parte alta da estante, com acesso restrito ao professor. Os livros que as crianças tinham acesso eram aqueles considerados empobrecidos esteticamente, com histórias curtas, vocabulário superficial e imagens estereotipadas, contrários aos do PNBE, que passam por um crivo antes de chegarem às escolas e são livros produzidos para provocarem a formação estético-literária das crianças.

\footnotetext{
${ }^{3}$ A sigla acima trata da Fundação Maria Cecília Souto Vidigal, que trabalha com crianças de zero a três anos e financia diversas pesquisas da primeiríssima infância com temas relacionados às áreas da Saúde e Educação. Nesta ocasião, um edital especial se abriu e, em parceria com a Fundação de Amparo à Pesquisa do Estado de São Paulo, a pesquisa supracitada foi financiada.

${ }^{4}$ Este projeto foi coordenado pelas Professoras Doutoras Cyntia Graziella Guizelim Simões Girotto e Renata Junqueira de Souza, no qual fomos colaboradoras.
} 
Ao nos referirmos sobre primeiríssima infância (crianças de até três anos), ainda será necessário que os proponentes dessa política entendam melhor a especificidade da idade, pensando em livros que atendam às necessidades das crianças, relacionadas ao período de seu desenvolvimento e ligados à manipulação e à exploração do objeto-livro em todos os sentidos do corpo. Em relação aos anos seguintes da Educação Infantil, no acervo do PNBE é possível localizar livros para as crianças explorarem, com uma riqueza estética e literária.

Com esse panorama inicial, nos propomos a discutir questões sobre possibilidades de atuação intencional e bem pensada com o livro de literatura infantil existente nas escolas e relativos ao acervo do PNBE, com a preocupação de estabelecimento de reflexões acerca da realidade escolar vivida por professores e crianças, considerando a especificidade de ser mediador da relação dessas crianças pequenas com o mundo.

\section{Tem um livro de literatura infantil aqui: o que faço?}

Conforme dados de Girotto e Souza (2010), os professores reconhecem a necessidade e importância da leitura e literatura infantil no trabalho pedagógico realizado com as crianças pequenas, porém, parecem desconhecer e não tratar a leitura como uma prática cultural e poucos conhecem livros de literatura infantil, ilustradores, autores e suas características. Assim como qualquer outro tipo de texto, os de literatura infantil têm aspectos próprios, estão encharcados de especificidades, desde a sua produção e editoração, relacionadas às escolhas de cores, tamanhos, texturas, materiais, letras, ilustrações, o que, em nossa compreensão, é conteúdo a ser apropriado pelo professor para a qualificação do trabalho desenvolvido com as crianças em turmas de Educação Infantil.

Como notado em pesquisa em andamento financiada pelo PROCAD/MEC, em quatro universidades brasileiras ${ }^{5}$, é fato que tais instituições, não possuem em seus cursos de Letras e Pedagogia, uma disciplina voltada ao ensino da leitura da literatura infantil para as crianças, esvaziando as possibilidades de formação plena dos professores para uma atuação potencialmente mais qualitativa e humanizadora. Essa ausência prejudica a apropriação de conhecimentos essenciais à constituição de um perfil docente-leitor, a partir da relação e

\footnotetext{
${ }^{5}$ As universidades que compõem esta pesquisa, intitulada "Leitura nas licenciaturas: espaços, materialidades e contextos na formação docente", são Unesp em dois campi, Marília e Presidente Prudente; Universidade de Passo Fundo; e Universidade Federal do Espírito Santo).
} 
contemplação da literatura como arte; tampouco possibilita que os graduandos tenham condições de aprender a pensar em um trabalho educativo provocador de novas necessidades humanizadoras nas crianças, dentre as quais a necessidade de ler.

Essa constatação provoca-nos a entender, do ponto de vista da Teoria HistóricoCultural, o que é leitura, literatura e como se configura o desenvolvimento de capacidades psicológicas tipicamente humanas e sua historicidade:

10 - o tempo humano é história, tanto individual como social, e a atividade produtiva (transformadora) dos homens é ponto central para compreender o desenvolvimento humano;

2 - - a psique humana possui um desenvolvimento histórico e uma relação de dependência essencial dos fenômenos psíquicos com respeito à vida e à atividade social;

3 - - a psique humana é mediatizada, e as funções psíquicas superiores são o produto da própria interação mediatizada pelos objetos criados pelo homem. (SHUARE, 1990 apud FACCl, 2004, p. 153).

Tal abordagem histórico-cultural do desenvolvimento da inteligência e da personalidade humana remete-nos à compreensão de que o Outro é fundamental no processo formativo de características humanas desde seu nascimento e que o tipo de relação de cada pessoa com o mundo é mediada pelo Outro - materializado na figura de uma pessoa, de um objeto, de um espaço, por exemplo.

Dessa ótica, reflexões sobre o papel da escola e do valor do ensino para a humanização exigem discussões baseadas na compreensão da escola como parte integrante de uma sociedade que tem em si objetivos próprios para a formação do sujeito, os quais podem ser inclusivos ou excludentes. Se, nas pesquisas citadas acima, notamos que os professores não leem para as crianças, percebemos também que, em sua formação inicial, não tiveram disciplina que os ensinasse a como ler para e com os pequenos, e/ou a criar espaços de ação direta com os objetos da cultura humana dados a ler.

O modo como a educação está configurada tem razões históricas para a atual defasagem e desqualificação da ação docente, porém, a fim de conseguirmos uma melhor formação inicial torna-se imprescindível aguçada militância em favor da profissionalização dos pedagogos, o que implica em instrumentalização teórica e científica de sua prática. $\mathrm{A}$ superação de suas condições objetivas atuais, em nebulosas problemáticas, determinantes de sua natureza e implicações, diga-se, não só pedagógicas, mas também sociais, exige um 
esforço conjunto de vários setores aí implicados, como as próprias Universidades, Secretarias de Educação e as esferas governamentais, em nível estadual e federal, responsáveis pelos programas de políticas públicas.

No bojo da luta por uma infância leitora e literária, centram-se as políticas públicas de leitura a elas destinadas, buscando-se endereçar achados de pesquisa como as aqui já citadas e sua divulgação mediante a socialização de possíveis resultados, como os expostos neste texto, dentre outras ações.

No entanto, para repensarmos as práticas pedagógicas preocupadas com a elaboração de atividades que promovam o interesse das/nas crianças, segundo Facci (2004, p. 199), é emergente a clareza de que “[...] c) o interesse pela atividade é um ingrediente fundamental no processo de aprendizagem [...]", e se o objetivo do professor centra-se no desenvolvimento máximo das crianças, como senhor da própria ação, detentor do saber e do fazer na escola da infância, cumpre realizar uma ação coerente e produtiva com tais metas. Por isso, emerge desse processo como uma necessidade da atuação docente, o planejar intencionalmente tais atividades, como por exemplo, as de leitura literária.

Ao pensarmos, então, em tal planejamento, um bom expediente de ensino tem sido a abordagem das estratégias de compreensão leitora propostas por Harvey e Goudvis (2008), difundidas no Brasil, por Girotto e Souza (2010). Tais estratégias são consideradas pelas pesquisadoras brasileiras como ferramentas metacognitivas que podem auxiliar o professor no trabalho pedagógico e, até mesmo, em um trabalho de sua própria formação como leitor.

É sabido que os leitores experientes já fazem o uso das estratégias, por vezes, sem uma tomada de consciência delas. Com base nisso, a proposta incide justamente na conscientização de tais usos de ferramentas cognitivas - que se tornam metacognitivas mobilizadas por meio do ato de ler. Isso significa que, nas propostas educativas, o próprio professor torna-se um 'modelo leitor' para as crianças na escola da infância.

Foucambert (2008), expoente pesquisador francês, tem estudado os modos e ações de ser leitor, com vários exemplos básicos de como, inconscientemente, vamos apropriando-nos da leitura nos espaços onde, por exemplo, presenciamos leitores, lendo, ou onde testemunhamos o uso dos materiais dados a ler, apenas observando o modo como folheiam os livros, os suportes digitais (da direita para a esquerda), ou, ainda, como os seus olhos se movimentam, e, por vezes, os dedos, e como estes percorrem as páginas (da 
esquerda para a direita no mundo ocidental), como seguram o livro, e até mesmo as expressões faciais daqueles que se deliciam com o texto.

Figuram nessas reflexões, a relevância do 'outro', aquele que, 'invadindo' minha vida interior, me constitui. Trata-se de uma conformação de sujeito leitor somente realizada mediante à palavra do outro, à sua voz, ao seu gesto, à sua ação.

Bakhtin (2003, p. 370), célebre filósofo da linguagem, com o qual muito aprendemos, ao falar sobre a linguagem, enfoca e dá valoração, igualmente, à importância do outro, enfatizando:

Eu vivo em um mundo de palavras do outro. E toda a minha vida é uma orientação nesse mundo; é reação às palavras do outro (uma reação infinitamente diversificada), a começar pela assimilação delas (no processo de domínio inicial do discurso) e terminando na assimilação das riquezas da cultura humana (expressas em palavras ou em outros materiais semióticos).

Esse mesmo autor ressalta ainda:

Para cada indivíduo, essa desintegração de todo o expresso na palavra em um pequeno mundinho das suas palavras (sentidas como suas) e o imenso e infinito mundo das palavras do outro são o fato primário da consciência humana e da vida humana, que, como tudo o que é primário e natural, até hoje tem sido pouco estudado (conscientizado), pelo menos não foi conscientizado em seu imenso significado essencial. [...] As complexas relações de reciprocidade com a palavra do outro em todos os campos da cultura e da atividade completam toda a vida do homem. (BAKHTIN, 2003, p. 379).

As crianças, dessa ótica, estão mergulhadas em um mundo que é do outro, aqui do outro -autor e/ou leitor proficiente, ou em formação. Um mundo leitor do qual precisam se apropriar. Na Educação Infantil, por exemplo, tendo como base todas as funções sociais dos objetos de leitura, os diversos gestos, as ações, os modos de ler, bem como as expressões e as emoções a eles relacionados, constituem o ser leitor, considerando, nesse processo, as atitudes leitoras, o seu próprio pensar e o seu desenvolvimento como criança leitora em formação.

Depreendemos, já da primeira citação, quão notaria é a atitude responsiva no ato leitor, pois a ação-voz do outro-autor que me chega, é a dirigente de minha atitude em/para ler. Segundo Roger Mello, prêmio IBBY de Literatura Infantil 2015, “É a pilotagem para que o meu eu-leitor possa enveredar pela (re) descoberta do texto gráfico e híbrido expresso em palavras escritas e imagens, por exemplo, quando se fala em Literatura Infantil." (MELLO, 2016). 
Como educadores preocupados com esta formação da criança, entendendo o valor de nossa ação como criadores de situações e espaço-tempo de mediação de leitura, também a 'pilotagem' que rege nossas ações didáticas não pode ser a de uma educação literária regida sob a batuta de um ensino formal articulado a uma escolarização dirigida para formar mão-de-obra (GENTILI, 2002), voltada a pensarmos à criança como 'suprimento para o mercado de trabalho'. Em lugar disso, urge que a escola redirecione-se à formação do leitor em sua plena capacidade, tornando-o sensível ao seu entorno e questionador em relação a si, ao outro e ao mundo.

O que temos visto comumente nos noticiários é o fato de que muitos de nós temos as capacidades primárias e mais primitivas e elementares do humano, não respeitando o espaço-tempo do outro, a dor do outro, o capital de todos. Todavia, se somos os únicos 'seres vivos racionais' a adquirir uma segunda natureza social - já que a biológica é essencial, mas não suficiente para a vida em sociedade -, torna-se imprescindível nos apropriarmos das capacidades especificamente humanas, como a capacidade de pensar, planejar, imaginar, sentir controlando as emoções, ler, escrever, representar, dentre outras, como a de agir humanamente, e, igualmente, de se expressar e de operar tecnologias.

Se assim o é, deveríamos contribuir para a formação do 'humano' em cada criança, desenvolvendo tais capacidades superiores, por meio de uma Educação Literária desde a infância pequena. Nossa luta é para figurar esta importância em cursos de formação inicial e continuada de professores, a fim de que os futuros professores possam ir se apropriando dessas funções para objetivá-las em ações didáticas congruentes junto às crianças pequenas, desde as consideradas 'mínimas' na Educação Infantil, mas fundamentais, como ouvir, dar voz e vez aos pequenos, ensinar o respeito ao colega e aos seus materiais, dentre outros aspectos.

Do narrar histórias às crianças, emerge a necessidade, paralelamente, de haver vez em tempos e espaços para as próprias narrativas infantis.

Narrar uma história pode ser um sonho, uma fofoca, um acontecimento, ou aquela que vimos nas páginas de um livro. Pode ser a lembrança da voz da mãe durante uma cantiga de ninar, a voz rouca e cansada daqueles cabelos brancos, que com suavidade contavam curiosas, fantásticas e inesquecíveis histórias. Pode ser o filme que assistimos na televisão, ou algo que nos contaram e simplesmente gostamos. Enfim, tudo faz parte 
de um enredo de narrativas que ouvimos, contamos e recontamos a todos os momentos, e que estão envolvidas em nossas vidas constantemente, em diferentes manifestações e situações. (CAMPOS, 2009, p. 2).

O ensino do ato de ler e do ler a literatura deve ser oportunizado desde a mais tenra idade, sem o objetivo de alfabetizar precocemente, mas de fazer com que as crianças explorem esses objetos de acordo com o seu período de desenvolvimento e se humanizem.

As estratégias de compreensão leitora possuem um modelo de estrutura para o trabalho com a leitura, que basicamente consiste em uma oficina de 60 minutos distribuídos da seguinte forma: Aula introdutória (5-10 minutos); Prática Guiada e Leitura Independente (35-50 minutos); Partilha em grupo e avaliação (5-10 minutos) (GIROTTO; SOUZA, 2010).

$\mathrm{Na}$ aula introdutória, de acordo com as autoras, o professor explica a estratégia eleita e serve como modelo para as crianças entenderem o seu uso enquanto realiza a leitura. Por exemplo, na conexão texto-leitor, em que uma palavra ou frase do livro devem remeter à minha vida, ao ler o título do livro o professor já pode dizer algo que se lembrou da sua vida.

Na prática guiada, quando as crianças já são leitoras, o professor auxilia os grupos em relação às dúvidas da estratégia eleita. Depois, vão para a leitura independente, em que leem e fazem as estratégias sozinhos, podendo ser registradas por meio de post-its, cartaz âncora ${ }^{6}$, no próprio caderno, dentre outras formas que o professor pode planejar e eleger. A avaliação é um momento coletivo em que as crianças podem comentar como foi a realização das estratégias e se gostaram do livro, etc.

Esta estrutura não é fechada, é apenas um modelo e uma ideia, cada professor deve fazer de acordo com as necessidades infantis. Para o trabalho de crianças da Educação Infantil, ${ }^{7}$ em que as crianças não são alfabetizadas, a professora pode servir como escriba e a leitura independente pode ser anulada, sendo realizada apenas a prática guiada, mas com todas as crianças da turma.

\footnotetext{
${ }^{6}$ O cartaz âncora como um exercício de sistematização figura no texto de Girotto e Souza (2010). Trata-se da possibilidade de resgate das prováveis conexões, por exemplo, surgidas durante o ato de ler. Por exemplo, pode-se fazer colunas, em que são registradas conexões e/ou estratégias utilizadas. Por exemplo, a despeito da conexão texto-leitor, haveria uma coluna para registro da palavra ou frase que nos remete à nossa vivência e em outra coluna, à nossa lembrança.

${ }^{7}$ Caso haja interesse, sugerimos a leitura de Trabalho de Conclusão de Curso, realizado na Educação Infantil, intitulado "Estratégias De Leitura e Literatura Infantil: contribuições para a formação da compreensão leitora em crianças de idade pré-escolar." (COSTA, 2015).
} 
As estratégias podem ser categorizadas em seis, em seu conjunto. São elas: conexão texto-leitor; conexão texto-texto; conexão texto-mundo; inferência; sumarização; síntese; perguntas ao texto. As estratégias estão interligadas e sistematicamente operam no ato de ler, durante o processamento leitor. Didaticamente, a seguir, abordamos em separado, em uma tentativa de aguçar o apreço de professores da infância pelo acervo do PNBE contido nas escolas, e, concomitantemente, ao explorar as estratégias, exemplificar formas de encaminhamentos de explorá-las junto às crianças.

\section{a) Conexões}

A Conexão texto-leitor propicia o ato de conectar-se por meio de uma palavra, frase ou tema do livro; por ela, a criança relembra algo ocorrido em sua vida, por isso, há a indação: "Sugerimos livros cujos temas sejam facilmente reconhecidos pela criança, pois estes Ihes permitem estabelecer relações com suas vivências." (GIROTTO, SOUZA, 2010, p. 71).

Figura 1- Capa do Livro "Rosita Maria Antonia Martins da Silva".

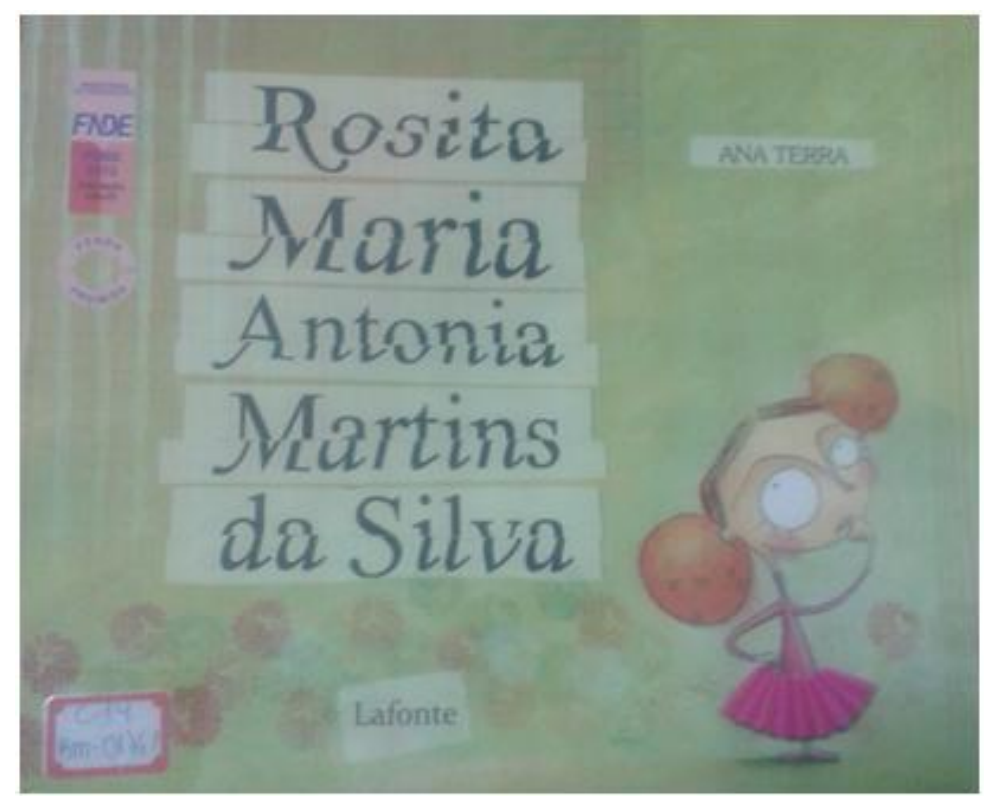

Fonte: Reproduzido pelas autoras

No livro Rosita Maria Antonia Martins da Silva, de Ana Terra, cujo nome da menina já é o título da história, pode-se relacionar o nome com o das próprias crianças, por ser extenso, tal qual o de muitas, ou então, por conter o sobrenome Silva, presente em muitas 
famílias. Ademais, a história narra os desejos de Rosita, os quais podem expressar o de muitas crianças, que podem fazer links com outros desejos da turma. Desse ponto de vista, por sua estrutura narrativa e temática é um livro possível de focar a exploração conjunta da Conexão Texto-leitor.

A despeito da Conexão Texto-texto, igualmente, mediante uma frase, palavra ou tema, o leitor "[...] estabelece relações com outro texto do mesmo gênero ou de gêneros diferentes." (SOUZA; GIROTTO, 2010, p.68).

Figura 2- Capa do Livro "Cuidado com o menino!"

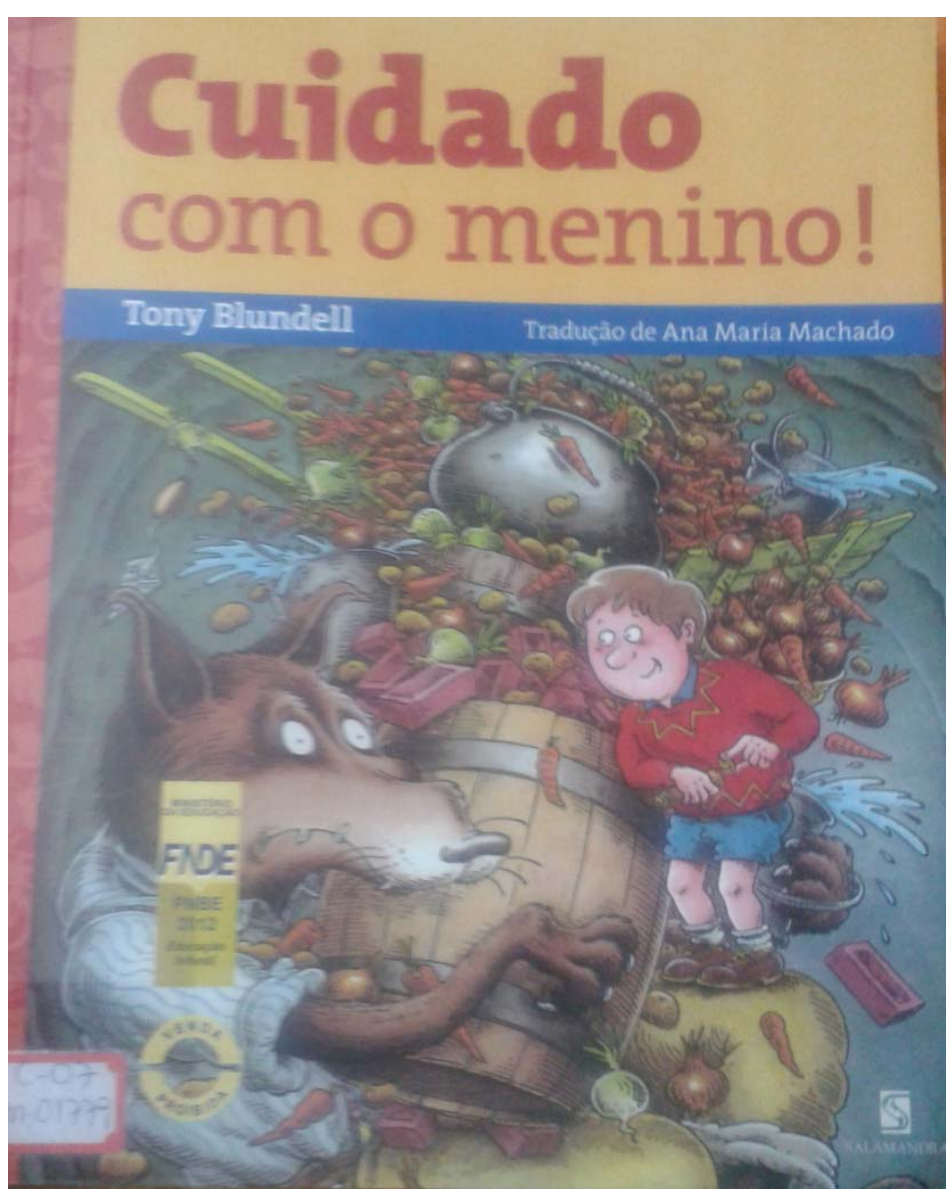

Fonte: Reproduzido pelas autoras

Este livro narra a história do lobo que se aproxima do menino com a intenção de comê-lo, porém, por vezes o menino consegue se safar e, ao final da narrativa, prega uma peça no lobo, deixando-o preso e saindo ileso. Dentre as histórias de lobo que as crianças conhecem, neste livro, por toda a 'malandragem' inerente a figura do lobo para tentar comer o menino, as crianças logo podem realizar a Conexão texto-texto com a história da 
Chapeuzinho Vermelho ou a história Os três porquinhos. Por este motivo, para a realização desta estratégia, é necessário que a criança tenha tido contato com histórias diversas, em versões variadas, pois, quanto maior for o seu repertório leitor, maiores serão as possibilidades de realizar conexões desta natureza.

Já na Conexão Texto-Mundo, como nas anteriores, o leitor parte do texto ao mundo, em que conexões devem ser "estabelecidas entre o texto lido e algum acontecimento mais global, por exemplo, da cidade em que o leitor vive ao mundo em que vivemos." (SOUZA; GIROTTO, 2010, p. 69).

Figura 3- Capa do Livro "O homem do saco"

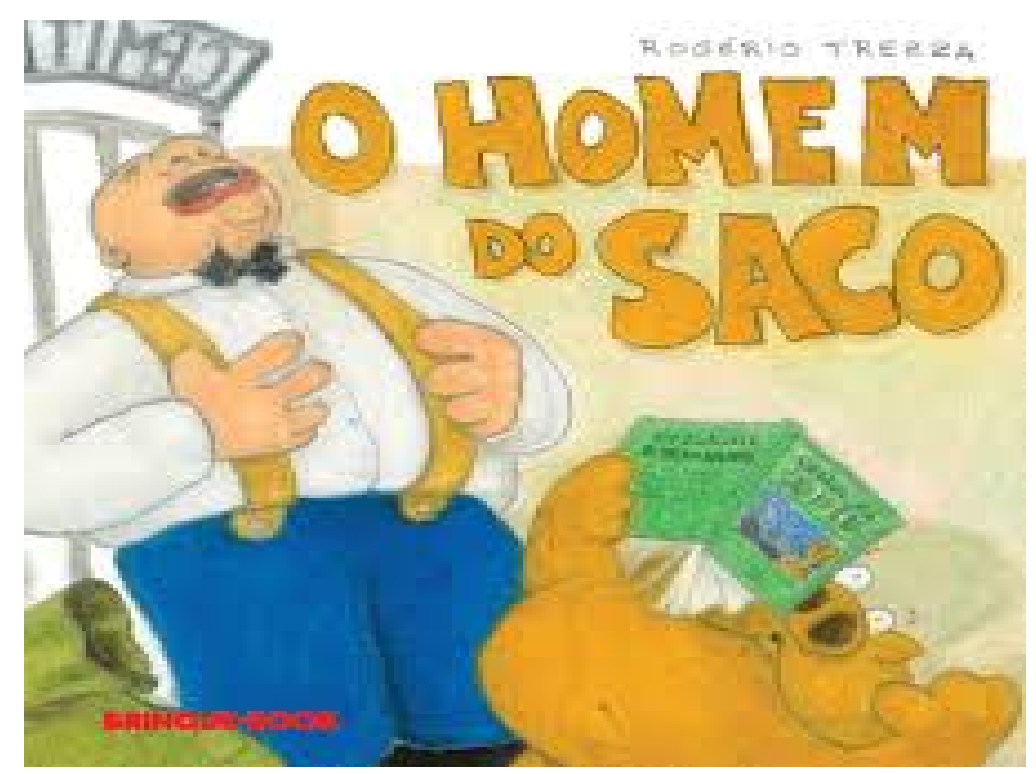

Fonte: Reproduzido pelas autoras

Em O homem do saco, há a história de um porquinho que, ao ficar só em casa, foge das ligações de um homem denominado como "O homem do saco". Com medo e pela ausência dos pais, acredita que esse homem esteja em busca dele. Ao final, o porquinho descobre que aquele que carrega o saco, é conhecido como tal por ser um trabalhador da reciclagem. Muito embora o grande tema desta obra não seja a reciclagem, talvez as crianças venham a fazer uma conexão do texto com o mundo, que busca por uma ação humana mais sustentável, por cidades ecológicas, pela conservação do planeta. 
b) Inferências

Inferência é uma estratégia que exige a atenção especial do leitor tanto para as expressões verbais, quanto para a linguagem visual (ainda que o texto não-verbal, como parte integrante da obra ilustrada, na concepção de um texto híbrido, não seja território restrito desta estratégia, já que em todas elas a ilustração figura como elemento central, a despeito da falsa ideia da supremacia do texto escrito sobre a ilustração e a materialidade da obra), pois só assim se pode supor a sequência cronológica dos fatos da narrativa, aquilo que ocorrerá na história ou a razão pela qual o autor e/ou ilustrador optaram por determinada palavra, expressão e ilustração.

Figura 4- Capa do livro "O Gato Viriato, O Pato."

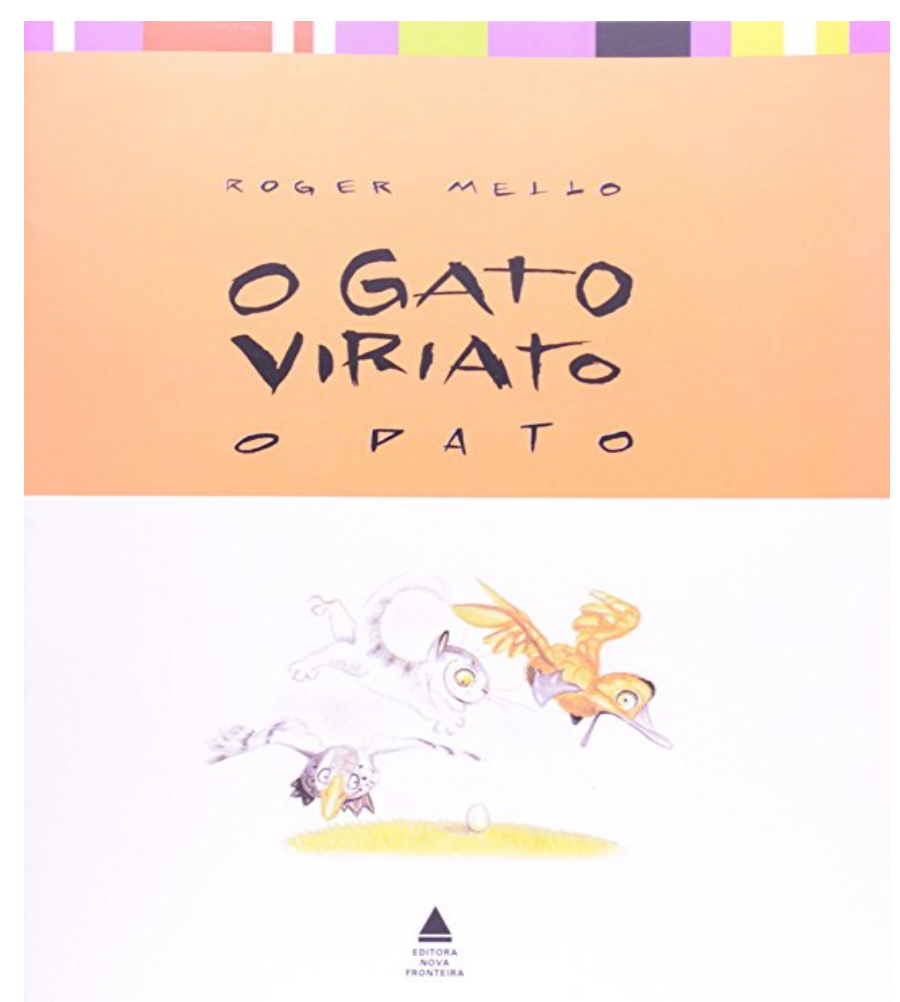

Fonte: Reproduzido pelas autoras

'O Gato Viriato e o pato' é um livro de imagens. Nesta narrativa visual, um dos personagens centrais da obra, o gato faz par junto da figura de um pato, tenta num primeiro momento comê-lo, porém, acaba se tornando amigo dele, carrega-o para todo lado e tenta ensiná-lo a voar (sem sucesso). Ao verem a amizade entre gato e pato, outros gatos tomam Viriato como motivo de chacota, porém, nesse momento, de clímax para 
desfecho da narrativa, a inferência é requerida e o resultado é surpreende ao leitor: pato sai voando carregando gato, enquanto os outros surpresos e, ao que transparece, com um 'pingo' de inveja. Um bom expediente em narrativas visuais como esta é instigar as crianças, leitoras em formação, a pensarem nas possibilidades que a linguagem visual nos dá, pela própria capa e pelo conteúdo implícito pelos vazios e frestas de cada página ilustrada.

Maria Alice Faria (2006) uma das primeiras estudiosas contemporâneas ao debater o uso da literatura infantil em sala de aula traz indicativos positivos sobre a exploração das ilustrações e sua relevância para a formação da compreensão leitora. De maneira clara e objetiva, focando a referida obra de Roger Mello, no capítulo quarto, faz referência, especialmente, aos ditos 'brancos'; 'vazios' que muito contribuem para aguçar o enredamento do leitor mirim, mas enfatiza que "[...] o autor deve ser muito claro e preciso nos elos de encadeamento de modo que cada quadro tenha traços bem visíveis de sua ligação com o quadro anterior e elementos que 'puxam' a narrativa para o quadro seguinte, até o desenlace." (FARIA, 2006, p. 58), pois como a literatura já tem seu viés polissêmico, o autor dos livros de imagens devem se atentar muito para que a narrativa seja compreendida.

\section{c) Visualização}

A Visualização para muitos estudiosos é um tipo de inferência, justamente por sua essência que diz respeito às imagens mentais formadas em nossa mente a partir de elementos detalhados provenientes do texto, porque leitores "[...] criam cenários e figuras em suas mentes enquanto leem, fazendo com que eleve o nível de interesse e, assim, a atenção seja mantida." (SOUZA; GIROTTO, 2010, p.85). 
Figura 5- Capa do Livro "Quem soltou o Pum?”

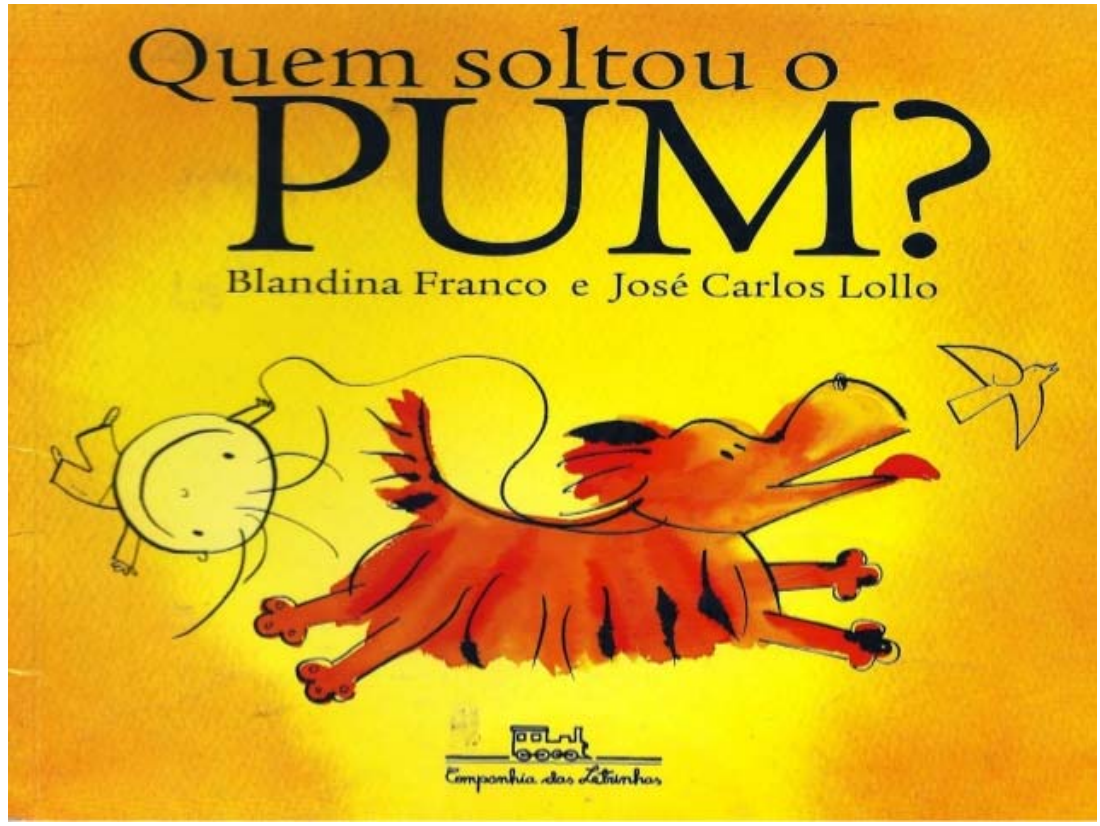

Fonte: Reproduzido pelas autoras

A Visualização precisa ter um texto bem descritivo para conseguirmos realizar as ações e montarmos o cenário mentalmente. Este livro Quem soltou o Pum? pode ser apresentado às crianças sem o contato inicial com a capa. A propositura remete a solicitação de que a imaginem pelas cenas narradas pela história. Ao ler, o professor da infância, não apresenta nenhuma das imagens, por exemplo, e, ao final da leitura, pode ser discutido quem soltou o pum e quem é o pum. Certamente as crianças farão também muitas conexões Texto-Leitor, mas ao visualizarem a personagem do livro, as visualizações feitas serão refeitas e, a partir disso, o professor pode recontar o livro, mostrando as imagens. Isto pode ser feito também com textos poéticos, textos científicos, de modo a estimular a imaginação.

\section{d) Sumarização}

Sumarização é precedente à Síntese e tais estratégias de leitura acabam se integrando, por isso, é possível abordá-las num mesmo dia para as crianças. A Sumarização é justamente discutir com as crianças sobre todo o conteúdo da obra e junto delas poder elencar quais pontos são importantes, mas não são os essenciais no texto, podendo separá-los para ir sumarizando a obra e, na sequência, realizar uma síntese. A Síntese é a estratégia em que, a partir dos pontos essenciais elencados na Sumarização, as crianças 
resumem o texto ofertado pelo educador. Vale ressaltar que "Isso [ainda] os ajuda a memorizar e a atribuir significados aos fatos." (SOUZA; GIROTTO, 2010, p. 103).

e) Perguntas ao texto

Por fim, Perguntas ao texto representa todo questionamento oriundo desde o momento em que o leitor mirim venha a se deparar com o material dado a ler, seja pela escolha das palavras, das letras, das cores, da materialidade do livro, dos seus apelos sensoriais, e, a partir disso tudo, vai buscando encontrar as possíveis respostas por meio da leitura partilhada com o professor da infância.

Desse ponto de vista, focar a abordagem das estratégias de compreensão leitora em atividades de leitura literária na escola da infância é trazer contribuições tanto para a formação das crianças, quanto para a do professor, que com elas possam vivenciar experiências enriquecedoras de aprimoramento das potencialidades leitoras, tanto a capacidade e a atitude de ler se tornam mais aguçadas, como pode ele questionar e buscar elementos para as ações educativo-didáticas do seu cotidiano profissional.

Ao considerarmos os projetos gráfico-editoriais das obras destinadas às crianças presentes no mercado editorial, é possível entender que os livros, hoje em dia, podem aparecer em diversos tipos de materiais, conhecidos como livros de banho, cartonados, emborrachados, olfativos, audíveis, táteis (SOUZA; BORTOLANZA, 2012) e muitos outros com boa qualidade estético-literária. Assim, além de proferido pela professora, deveriam ser materiais explorados na ação direta das crianças, considerando-se principalmente as especificidades dos pequenininhos. Podem, portanto, ser oportunizadas situações em que manipulem, sintam, cheirem, ouçam e tenham contato com o livro e experiências leitoras desde bebês.

Quando a fala estiver presente e as crianças já conseguirem se expressar, a professora pode realizar a leitura de livros com o uso das estratégias, sem precisar definir as nomenclaturas e, sim, as ações contidas no ato de ler. Vale ressaltar que, para haver interesse na atividade, é essencial que a professora escolha um livro pensando em ações a serem desenvolvidas com as suas crianças, pois cada sala tem suas preferências por histórias: alguns podem gostar mais de bruxas, outras de duendes, outras de princesas, portanto, a professora deve conhecer as suas crianças. 
Para promover as vivências das estratégias, ela pode pedir às crianças o registro após a história e questionar os desenhos, e, ainda, avaliar se a proposta foi entendida ou não. No decorrer do trabalho pode já ir notando o uso das estratégias no momento em que começa uma leitura, pois, as crianças, 'sacadas' como são, querem participar e contar tudo de si para os outros.

Nesse processo pedagógico, ao ter um livro em mãos, o professor o explora em suas minúcias, para poder elaborar propostas que interessem, provoquem e criem motivações nas crianças, em busca do desejo de sempre querer ler e ensinar atos de leitura.

\section{Considerações Finais}

Este texto se propôs a dialogar com professores que não tiveram formação para trabalhar com a leitura e literatura na grade curricular do curso de Pedagogia, mas que, ao notarem o valor do trato da literatura infantil na escola, principalmente em turmas da primeira infância, buscam alternativas para pensar nessa prática pedagógica.

Trouxemos em poucas páginas um pouco de nossa trajetória dos últimos anos, em que sentimos a necessidade de estudar e entender mais sobre os livros de literatura e os processos que passam até que cheguem em nossas mãos e nas mãos das crianças. A discussão ainda será aprofundada porque pretendemos compreender até que ponto o capital interfere na publicação e como a formação leitora de um autor-escritor interfere em seu processo de criação.

Compreendemos que esses elementos trazidos nos limites deste texto, possíveis de serem aprofundados, podem nos ajudar no trabalho da leitura e literatura em ambientes escolares, de modo que consigamos enxergar a literatura infantil como uma fonte da cultura humana e da arte, que muda com o tempo, de acordo com a necessidades da sociedade em que faz parte. Consideramos, também, este trabalho com a leitura é desenvolvedor de funções psíquicas superiores, tais como a memória, percepção, atenção, concentração, controle de conduta, além da apropriação e desenvolvimento da linguagem.

Desse modo, escrevemos com a intenção de afetar o nosso interlocutor, com contribuições reais para o fazer docente, por isso, para escrever um texto fazemos sempre diálogos com as vozes que nos chegam por meio de vivências como filhas, professoras, 
alunas, mães, leitoras de literatura infantil, de textos que tratam do desenvolvimento humano, da leitura, da literatura, das ilustrações e tantas outras experiências que ecoam em nós. Assim esperamos que esta leitura também afete e colabore para futuras ações docentes.

\section{Referências}

BAKHTIN, Michael. Estética da Criação Verbal. São Paulo: Martins Fontes, 2003.

BRASIL. Ministério da Educação. Conselho Nacional de Educação.Câmara de Educação Básica. Resolução no05, 17 de dezembro de 2009. Fixa as Diretrizes Curriculares Nacionais para a Educação Infantil. Brasília, 2009. Disponível em:

<http://portal.mec.gov.br/dmdocuments/rceb005_09.pdf>. Acesso em: 12 abr. 2015.

CAMPOS, K. C. Literatura infantil e a narração de histórias: a Constituição da criança como narradora. In: COLE - CONGRESSO DE LEITURA DO BRASIL: "É preciso transver o mundo", 17., 2009, Campinas. 2009. Anais.... São Paulo, 2009.

COSTA, Yngrid Karolline Mendonça . Estratégias de Leitura e Literatura Infantil: contribuições para a formação da compreensão leitora em crianças de idade pré-escolar. Trabalho de Conclusão de Curso (Graduação em Educação) - Universidade Estadual Paulista Júlio Mesquita Filho, UNESP, Marília, 2015.

FARIA, M.A. Como usar a literatura infantil na sala de aula. 3. ed. São Paulo: Contexto, 2006, 156 p. (Coleção Como usar na sala de aula).

FACCI, M.G.D. Valorização ou esvaziamento do trabalho do professor? um estudo críticocomparativo da teoria do professor reflexivo, do construtivismo e da psicologia vigotskiana. Campinas, SP: Autores Associados, 2004.

FOUCAMBERT, J. Modos de ser leitor: Aprendizagem e ensino da leitura no ensino fundamental. Tradução de Lucia P. Cherem e Suzete P.Bornatto. Curitiba: Editora UFPR, 2008.

GENTILI, P. Do ponto de vista neoliberal, os sistemas educativos enfrentam hoje uma profunda crise de eficiência, eficácia e produtividade. 2002. Disponível em:

<http://www.projetoadia.com.br/not/128-pablogentili.htm>. Acesso em: 4 fev. 2015.

GIROTTO, C.G.G.S.; SOUZA, R.J. Estratégias de leitura: para ensinar alunos a compreender o que leem. In: SOUZA, R.J. (Org.). Ler e compreender: estratégias de leitura. Campinas: Mercado de Letras, 2010.

HARVEY, S.; GOUDVIS, A. Strategies that work: teaching comprehension for understanding and engagement. 2. ed. Portland, Maine: Stenhouse Publisher, 2008. 
MELLO, R. De feituras: escrita e ilustração. In: SEMINÁRIO DE LITERATURA INFANTIL E JUVENIL, 7., 2016, Passo Fundo. Palestra.

SOUZA, R. J.; BORTOLANZA, A. M. E. Leitura e literatura para crianças de 6 meses a 5 anos: livros, poesias e outras idéias. In: SOUZA, R.J.; LIMA, E.A. (Org.). Leitura e cidadania: ações colaborativas e processos formativos. Campinas: Mercado de Letras, 2012. p. 1-15. 